\title{
Cholinesterase estimations revisited: the clinical relevance
}

In 1986, Whittaker wrote 'Churchill-Davidson's editorial entitled "The succinylcholine story" in 1963 , highlighted probably for the first time in the UK, the role of serum protein polymorphism in drug sensitivity' [1]. Following a series of detailed family studies, in 1959 Kalow [2] concluded that individuals who had prolonged apnoea following succinylcholine administration were homozygous for an atypical form of cholinesterase, the product of a gene other than that found in unaffected people [3]. This led to the introduction of the term 'pharmacogenetics', and cholinesterase estimations became an important biochemical investigation in anaesthesia. Subsequently, the global burden of pesticide-related disease - particularly due to the potent inhibitors of cholinesterase activity, the organophosphates increased the importance of quantifying the activity of this enzyme in clinical practice. Most of the illhealth associated with exposure to organophosphates has been attributed to inhibition of the enzyme acetylcholinesterase in a range of nerve, neuromuscular (skeletal, smooth, cardiac) and glandular tissues where the enzyme plays a key role in cell-to-cell communication.

The existence of an esterase capable of hydrolyzing acetylcholine was suggested by Dale [4] and established by Loewi and Navratil [5]. The term 'cholinesterase' was proposed by Stedman and colleagues [6] for this enzyme. Subsequently, Alles and Hawes [7] demonstrated that cholinesterase in human erythrocytes differed in a preferred substrate from that in human plasma. The erythrocyte enzyme - and the enzyme in conductive tissues (in all excitable tissues: cholinergic or adrenergic, motor or sensory, peripheral or central nerve fibres, and all types of muscle fibres) was called acetylcholinesterase, as acetylcholine is preferentially hydrolyzed. The enzyme in plasma was termed 'butyrylcholinesterase', as it preferentially

Correspondence to: Lakshman Karalliedde, Medical Toxicology Unit and National Poisons Centre (London), Guy's and St Thomas' NHS Trust, Avonley Road, London, SE14 5ER, UK. E-mail: Lakshman.Karalliedde@gstt.sthames.nhs.uk; Tel: +44(0)207 771 5315/5202; Fax: +44(0)207 7715306

Accepted for publication January 2002 EJA 865 hydrolyzed butyrylcholine and was formerly more popularly known as pseudocholinesterase. The roles of butyrylcholinesterase and that of acetylcholinesterase in erythrocytes and plasma are not known with any certainty to date, and individuals who do not possess butyrylcholinesterase lead normal lives until they are exposed to succinylcholine.

Butyrylcholinesterase is involved in the hydrolysis of many therapeutic agents and, together with acetylcholinesterase in the blood, it acts as a site for phosphorylation by organophosphates, thus serving as scavengers [8]. Scavenging reduces the amount of organophosphate available for toxic effects at vulnerable targets. For both acetylcholinesterase and butyrylcholinesterase, several functions have been proposed that are not directly related to synaptic transmission, e.g. the regulation of protein-protein interactions during neurite outgrowth and synapse formation, the modulation of cell movements, and cell proliferation [9].

A variety of methods are now available for cholinesterase assays based predominantly on the measurement of the rate of hydrolysis of an ester catalysed by cholinesterase. However, as the 'normal range' is characteristic for each substrate and the rate of hydrolysis is temperature- and $\mathrm{pH}$-dependent, confusion has arisen in the interpretation of estimations when the exacting practice of recording the substrate, $\mathrm{pH}$ and temperature have been omitted [1]. There are several reasons for the confusion associated with cholinesterase estimations in relation to exposure to anticholinesterases (e.g. organophosphates and carbamates). There are many causes of decreased activity of cholinesterases that are not related to exposure to anticholinesterases: genetic, physiological (age, gender, pregnancy, etc.), iatrogenic (therapeutic agents), disease states, exposure to smoke fumes and, in some instances, of uncertain origin [10-12]. There are suggestions that dietary factors can influence cholinesterase concentrations. Low concentrations of cholinesterases have been observed in malnutrition [13]. Further, with the increasing popularity of traditional medicines containing plants or plant extracts capable of lowering cholinesterase activity (e.g. solanine and chaconine in potatoes, 
which are often used in African traditional medicines to treat human immunodeficiency virus infection; also huperazine $\mathrm{A}$ in Chinese folk medicine, which is three times more potent than physostigmine in inhibiting acetylcholinesterase), other causes of lowered cholinesterase concentrations need to be considered [14]. At an American Society of Anesthesiologists' annual meeting, an anaesthetist reported that butyrylcholinesterase was inhibited at about $1 \%$ of the glycoalkaloid dose needed to block acetylcholinesterase and 'that amount was detected in the blood of individuals who have consumed potatoes'. The US Department of Agriculture has documented cases of toxicity after potato consumption [15]. In addition, there is considerable interindividual variation, the coefficients obtained from plasma cholinesterase ranging from 15 to $25 \%$, while for erythrocyte acetylcholinesterase the range was rather less at $10-15 \%$. The above findings are compounded by the observation that successive monthly measurements or successive daily measurements - in healthy individuals revealed intraindividual variations $>20 \%$, which on occasions reached $40 \%$ [16].

Raised concentrations of acetylcholinesterase have been detected in the presence of neural defects in early pregnancy [17]. They may prove reliable indicators of changes developing during the course of the disease multiple myeloma, e.g. remission fulfilment [18]. The mean butyrylcholinesterase concentrations of chronic spinal pain patients were significantly higher than the mean concentrations in normal control volunteers [19]. The observation that concentrations decreased significantly during anaesthesia was considered to be of some value in the treatment of chronic pain. Acetylcholinesterase determinations made after myocardial infarction have enabled classification of such patients into four groups with defined prognostic values [20], and assays prior to discharge of such patients has been recommended. Some correlations have been reported during the course of tetanus infections [21] and following liver transplantation [1]. Aldridge, in 1953, provided reasons for the different sensitivities of butyrylcholinesterase and erythrocyte acetylcholinesterase for organophosphate inhibitors [22].

Since assays for blood cholinesterase activity have become relatively simple procedures, they continue to be used to assess the extent of human exposure to pesticides. The role of such assays in diagnosis is more accepted than their role in estimating severity or prognosis and recovery. In industrial or occupational exposures, the cholinesterase assay has a clear advantage over estimations of atmospheric contamination of pesticides because estimations of contamination and of rates of inhalation are difficult in agricultural or farming conditions. Furthermore, the equipment for such measurements is much less freely available. Moreover, atmospheric analysis does not take into consideration absorption by other routes such as the skin, a real hazard among those who mix and apply pesticides. Cholinesterase assays have to some extent ensured that prescribed safety precautions during manufacture and application have been implemented [23]. Clear correlations between succinylcholine apnoea and butyrylcholinesterase assays are established and have been found to be very useful in the diagnosis of prolonged response to drugs used during anaesthesia. However, the same cannot be said for exposure to anticholinesterases. Among the puzzles surrounding the widely used organophosphates is the persistent failure to correlate biochemical findings with the severity of the disease following their exposure [24]. In 1946, Comroe and colleagues observed that di-isopropyl-fluorophosphate - which is an organophosphate capable of lowering butyrylcholinesterase and erytrocyte acetylcholinesterase activity to zero - afforded less symptomatic relief to patients suffering from myasthenia gravis than neostigmine, which was a less potent inhibitor of cholinesterase. They agreed with the 'fallacy' of relating pharmacological and therapeutic effects of anticholinesterases to the cholinesterase-lowering activity, which had previously been suggested [25]. However, it is now known that the solubility properties of neostigmine and di-isopropyl-fluorophosphate may have contributed to Comroe and colleagues' observations. In 1963, Goldberg and colleagues [26], studying the carbamate compound 10854, observed that effects on animal behaviour occurred after doses that were considerably lower than those that produced overt symptoms characteristic of anticholinesterase action. Grob [27], reporting on the effects of sarin in human beings, commented that local ocular and respiratory manifestations of nerve gas poisoning may occur without any inhibition of plasma or erythrocyte cholinesterase. However, he noted that systemic manifestations were invariably accompanied by depression of activity of these enzymes but varied depending on the form of exposure. The plasma and erythrocyte cholinesterase concentrations at the time of onset of symptoms following a single exposure were depressed approximately by 60 and $50 \%$ of initial activity following inhalation, to 35 and $25 \%$ following ingestion of liquid, and by 15 and $10 \%$ after percutaneous exposure. He went on to state that following repeated exposures to nerve gases, there was no predictable correlation between the onset of symptoms and the precise levels of cholinesterase activity in both plasma and erythrocytes, except that both were depressed considerably to values below normal.

A review by Karczmar in 1984 [28] suggested that anticholinesterases might directly affect a 
second messenger as well as a transmitter system other than the cholinergic system. Monnet-Tschudi and colleagues [29], studying the toxic effects of the organophosphates chlorpyrifos and parathion and their oxide derivatives on foetal rat brain cell cultures, suggested that toxic effects and acetylcholinesterase inhibition were unrelated. Murata and colleagues [30] investigated the victims of the Tokyo subway attack 6-8 months following the event and observed the persistence of asymptomatic sequelae to sarin exposure in the higher and visual nervous systems that exceeded the turnover period of cholinesterase. This latter observation arouses a certain degree of concern. Similarly, there is debate at present about the consequences of exposure to pesticides (organophosphates in particular) during the neonatal period and early infancy [31]. Vulnerability of a developing nervous system to their action particularly during periods of intense activity such as the 'rapid brain growth spurt' is uncertain but arouses an intense and often emotive response. Further, the phenomenon referred to as 'imprinting' [32] adds to concerns. This suggests that exposure to a wide range of chemicals during the neonatal period produces unusual responses following further exposure to similar agents in adult life.

Thus, doubts expressed after good research in the late 1940s and 1950s continue to trouble us today despite some correlations reported with symptomatology during the acute cholinergic phase, development of the intermediate syndrome [33] and for weaning from ventilatory care [34]. It is useful to recall the words of Ladell [35]:

the degree of dysfunction in a cholinergic junction is not linearly dependent upon the amount of cholinesterases present for there are considerable reserves of enzyme at all sites and the amount required for efficient functioning is small in comparison with the total amount required. The percentage depression would be the same at all sites and in all tissues within the body - blood, brain, autonomic ganglia, muscles and glands - if the relative concentration of cholinesterase to inbibitor was the same everywhere after poisoning, which requires rapid penetration to all sites.

The most important consideration for the reluctance to accept cholinesterase estimations as the sole measurement of value in anticholinesterase exposure is that clearly one cannot attribute all aspects of illhealth following such exposures only to inhibition of cholinesterases. Certainly, the development of organophosphate-induced delayed polyneuropathy is not associated with cholinesterase depression [36]. The relatively lesser known applications of cholinesterase measurements in clinical medicine, e.g. myocardial infarction, the detection of neural birth defects, multiple myeloma, and the management of chronic pain and tetanus, certainly merit further study. The role of cholinesterase estimations in anaesthetic practice will continue to be valuable, for these enzymes are necessary for the hydrolysis not only of succinylcholine and mivacurium, but also for that of diamorphine, cocaine, esmolol, remifentanil, procaine and related local analgesics. Cholinesterase concentrations may also be depressed by a wide range of therapeutic agents that may be prescribed for subjects presenting for anaesthesia [37].

Finally, whatever the limitations, cholinesterase estimations remain the only useful biochemical tool in anticholinesterase exposure at present. However, there are doubts after nearly four decades that it can be described as a 'trusted tool'. Therefore, critical assessment is needed soon and, if necessary, the search for a more sensitive and reliable biochemical marker for anticholinesterase exposure (in particular organophosphate exposure) should be accelerated. Critical evaluation of alternatives such as carboxylesterase estimations and plasma $\beta-G$ levels is also required with some sense of urgency. Perhaps hair analysis, which has been successfully developed to detect long-term exposure to drugs of abuse, should also be considered for occupational exposures.

L. Karalliedde
Medical Toxicology Unit and
National Poisons Centre (London)
Guy's and St Thomas' NHS Trust
London, UK

\section{References}

1. Whittaker M. Cholinesterase. In: Beckman LS (ed.). Monographs in Human Genetics. New York, USA: Karger Baseil, 1986: Vol. 11.

2. Kalow W. Cholinesterase types. In: Wolstenholme GEW, O'Connor CM (eds). Biochemistry of Human Genetics. London, UK: J \& A Churchill, 1959: 39.

3. Evans RT. Cholinesterase phenotyping: clinical aspects and laboratory applications. Crit Rev Clin Lab Sci 1986; 23: 35-64.

4. Dale HH. The action of certain esters and ethers of choline, and their relation to muscarine. J Pharmacol Exp Ther 1914; 6: 147-190.

5. Loewi O, Navratil E. Uber humorale Ubertragbarkeit der Herznervenwirkung, XI. Uber den Mechanisms der Vaguswirkung von Physostigmin und Ergotamin. Pflugers Arch 1926; 214: 689-696.

6. Stedman E, Stedman E, Easson LH. Cholinesterase. An enzyme present in the blood serum of the horse. Biochem J 1932; 26: 2056-2066.

7. Alles GA, Hawes RC. Cholinesterases in the blood of man. J Biol Chem 1940; 133: 375-390. 
8. Masson P, Josse D, Lockridge O, et al. Enzymes hydrolyzing organophosphates as potential catalytic scavengers against organophosphate poisoning. J Physiol Paris 1998; 92: 357-362.

9. Greenfield S. Non-classical actions of cholinesterases: role in cellular differentiation, tumorigenesis and Alzheimer's disease. Neurochem Int 1996; 28: 485-490.

10. Wills JH. The measurement and significance of changes in the cholinesterase activities of erythrocytes and plasma in man and animals. CRC Crit Rev Toxicol 1972; 1: 153-202.

11. Jokanovic M, Maksimovic M. Abnormal cholinesterase activity: understanding and interpretation. Eur $J$ Clin Chem Clin Biochem 1997; 35: 11-16.

12. Swaminathan R, Widdop B. Biochemical and toxicological investigations related to OP compounds. In: Karalliedde L, Feldman S, Henry J, Marrs T (eds). Organophosphates and Health. London, UK: Imperial College Press, 2001: 357-406.

13. Tinoco-Ojanguren R, Halperin DC. Poverty production and health: inhibition of erythrocyte cholinesterase via occupational exposure to organophosphate insecticides in Chiapas, Mexico. Arch Environ Health 1998; 53: 29-35.

14. Nigg HN, Knaak JB. Blood cholinesterases as human biomarkers of organophosphorus pesticide exposure. Rev Environ Contam Toxicol 2000; 163: 29-111.

15. Larkin M. Foods could influence anaesthetic action. Lancet 1998; 352: 1362.

16. Brock A. Inter- and intraindividual variations in plasma cholinesterase activity and substance concentration in employees of an organophosphorus insecticide factory. $\mathrm{Br} \mathrm{J}$ Ind Med 1991; 48: 562-567.

17. Brennand DM, Jehanli AM, Wood PJ, Smith JL. Raised levels of maternal serum secretory acetylcholinesterase may be indicative of fetal neural tube defects in early pregnancy. Acta Obstet Gynecol Scand 1998; 77: 8-13.

18. Bessmel'tsev SS, Rybakova LP, Gritskevich NL, et al. Diagnostic and prognostic significance of blood-serum ceruloplasmin, acetylcholinesterase and total proteolytic activity in patients with multiple myeloma. Vopr Onkol 1999; 45: 398-404.

19. Cameron BM, Allen RC, Merril C. A prospective study of serum pseudocholinesterase levels in patients with chronic spinal pain: a preliminary study. Spine 2000; 25: 1917-1924.

20. Menache R, Kenda L, Shaked P, Schwartzman S, Lewinski U. The prognostic value of serum acetylcholinesterase in myocardial infarction. Theoretical and clinical considerations. Res Exp Med (Berl) 1982; 181: 181-187.

21. Porath A, Acker M, Perel A. Serum cholinesterase in tetanus. Anaesthesia 1977; 32: 1009-1011.

22. Aldridge WN. The differentiation of true and pseudocholinesterase by organophosphorus compounds. Biochem J 1953; 53: 63-67.

23. Gage JC. The significance of blood cholinesterase activity measurements. Residue Rev 1967; 18: 159-173.
24. Hatjian BA, Mutch E, Williams FM, Blain PG, Edwards JW. Cytogenetic response without changes in peripheral cholinesterase enzymes following exposure to a sheep dip containing diazinon in vivo and in vitro. Mutat Res 2000; 472: 85-92.

25. Comroe JH, Todd J, Gammon GD, et al. The effect of diisopropyl fluorophosphates (DFP) upon patients with myasthenia gravis. Am J Med Sci 1946; 212: 641-651.

26. Goldberg ME, Johnson HE, Knaak JB, Smyth HF Jr. Psychopharmacological effects of reversible cholinesterase inhibition induced by $N$-methyl 3-isopropyl phenyl carbamate (compound 10854). J Pharmacol Exp Ther 1963; 140 : 245-252.

27. Grob D. The manifestation and treatment of poisoning due to nerve gas and other organic phosphate anticholinesterase compounds. Arch Int Med 1956; 98: 221-239.

28. Karczmar AG. Acute and long lasting central actions of organophosphorus agents. Fundam Appl Toxicol 1984; 4: S1-S17.

29. Monnet-Tschudi F, Zurich MG, Schilter B, Costa LG, Honegger P. Maturation-dependent effects of chlorpyrifos and parathion and their oxygen analogs on acetylcholinesterase and neuronal and glial markers in aggregating brain cell cultures. Toxicol Appl Pharmacol 2000; 165: $175-183$.

30. Murata K, Araki S, Yokoyama K, et al. Asymptomatic sequelae to acute sarin poisoning in the central and autonomic nervous system 6 months after the Tokyo subway attack. J Neurol 1997; 244: 601-606.

31. Eriksson P. Developmental neurotoxicity of environmental agents in the neonate. Neurotoxicology 1997; 18: 719-726.

32. Tchernitchin AN, Tchernitchin NN, Mena MA, Unda C, Soto J. Imprinting: perinatal exposures cause the development of diseases during the adult age. Acta Biol Hung 1999; 50: 425-440.

33. Avasthi G, Singh G. Serial neuro-electrophysiological studies in acute organophosphate poisoning - correlation with clinical findings, serum cholinesterase levels and atropine dosages. J Assoc Physicians India 2000; 48 : 794-799.

34. Lee P, Tai DY. Clinical features of patients with acute organophosphate poisoning requiring intensive care. Intensive Care Med 2001; 27: 694-699.

35. Ladell WSS. The impracticability of deducing blood cholinesterase depression from clinical condition in organophosphorus poisoning. In: Maynard RLA, ed. Medical Review of Chemical Warfare Agents. London, UK: CDE TP 484, 1989: 133-136.

36. Johnson, MK. Molecular events in delayed neuropathy: experimental aspects of neuropathy target esterase. In: Ballantyne B, Marrs TC (eds). Clinical and Experimental Toxicology of Organophosphates and Carbamates. Oxford, UK: Butterworth-Heinemann, 1992: 90-113.

37. Karalliedde L. Organophosphorus poisoning and anaesthesia. Anaesthesia 1999; 54: 1073-1088. 